\title{
ENSINO DE ESTATÍSTICA E FORMAÇÃO DO PROFESSOR DE MATEMÁTICA NA PERSPECTIVA DA BNCC
}

\section{ARTIGO ORIGINAL}

SILVA, Luís Enrique Fernandes da ${ }^{1}$

SILVA, Luís Enrique Fernandes da. Ensino de estatística e formação do professor de matemática na perspectiva da BNCC. Revista Científica Multidisciplinar Núcleo do Conhecimento. Ano 05, Ed. 06, Vol. 13, pp. 67-81. Junho de 2020. ISSN: 24480959, Link de

acesso: https://www.nucleodoconhecimento.com.br/educacao/matematica-naperspectiva

\section{RESUMO}

O presente artigo relata sobre as dificuldades de aprendizagem em matemática, mais especificamente o aprendizado em estatística. Tem como objetivo examinar os resultados obtidos em pesquisas e estudos com o intuito de buscar a identificação dos problemas e soluções. Todavia, para essa problemática, a defesa está inserida no contexto da estatística. Para defender os argumentos que serão expostos adiante, é escolhido utilizar a metodologia de revisão biográfica em um aspecto qualitativo. Com isso, são utilizadas diversas plataformas de busca como Google Acadêmico, ScieLO, artigos em outras revistas, além do uso de teses de mestrado e dissertações de doutorado. Outrossim, é importante destacar sobre a escolha dos artigos, para estes, o critério foi a busca de pelo menos $90 \%$ em trabalhos com pelo menos 10 anos, todavia, outros devido a sua importância foram adicionados sem o critério temporal. Conclua-se que existem muitos desafios a serem solucionados no que tange o ensino de matemática. Por fim, é necessário rever, aprimorar e adaptar diversas práticas

\footnotetext{
${ }^{1}$ Graduado em Matemática e Especialista em Tecnologias Educacionais, Profissional da Educação Básica, Universidade do Estado de Mato Grosso - UNEMAT.
} 
educativas, tanto no âmbito da exposição didática do conteúdo, quanto à atenção perante o currículo.

Palavras-chave: Ensino de matemática, estatística, BNCC.

\section{INTRODUÇÃO}

O presente trabalho tem como tema as dificuldades no processo e ensinoaprendizagem de matemática na disciplina de estatística. Desta maneira, o tema em questão está inserido no contexto da primeira educação, onde tenta se vincular tanto a contribuição para o ensino, quanto para a inserção da matemática no cotidiano do aluno.

Desta forma, o problema a ser discutido é colocado na dificuldade que os alunos no Brasil têm no aprendizado de matemática. Com isso, com o advento do mundo moderno, não associar a educação as tecnologias e, situações cotidianas certamente trarão consequências danosas para a progressão do ensino.

Sob essa perspectiva, a hipótese tem como cerne que a BNCC possui papel importante em nortear o ensino de estatística e, traz apontamentos sobre os objetivos e metodologias, uma vez que possui qualidade de auxílio à prática pedagógica do professor, pois com o uso da prática do cotidiano, o aluno tem sob domínio a construção do seu próprio conhecimento.

Desta maneira, um ponto fulcral está inserido sobre a justificativa desta construção textual, onde é fácil notar que existe uma queixa recorrente sobre o aprendizado em matemática e, com isso, é necessário trazer instrumentos e fazer discussões sobre metodologias norteadoras da prática pedagógica.

Nesse contexto, a metodologia é o caminho no qual visa compreender o percurso que a pesquisa obterá o resultado, de forma a refletir: o objetivo, a justificativa e a fundamentação teórica, onde pressupõe que tudo tem conexão para obtenção dos dados, hipóteses. Para tanto, a seguinte pesquisa é de método qualitativo que permite 
ao pesquisador examinar os resultados obtidos através de revisão bibliográfica a fim de fundamentar os objetivos ilustrados anteriormente.

\section{DIFICULDADES DE APRENDIZAGEM EM MATEMÁTICA}

O conceito de aprendizagem é uma temática largamente debatida. Nesse sentido, é possível afirmar para os fins deste trabalho que a aprendizagem é o conjunto de conceitos, saberes, práticas e representações que o indivíduo soma a fim de entender a si próprio e o mundo que o cerca. Conforme mostra Ignez (2015, p.53) Aprendizagem, em Vygotsky, "é um processo de apropriação de conhecimentos, habilidades, signos, valores, que engloba o intercâmbio ativo do sujeito com o mundo cultural onde se está inserido". Desta maneira, conforme mostra Ignez em sua reflexão em Vygotsky, o indivíduo em sua prática de aprendizagem possui em seu ser um conjunto de esquemas e estruturas intelectuais.

Portanto, baseia-se num processo permanente que já se tem as primeiras construções no convívio familiar, com as culturas e tradições continuamente acrescentando e aperfeiçoando, na medida em que o convívio escolar, social e familiar se fundamente no interior do aluno.

Sendo assim, esse processo deve valorizar as diferentes modalidades que o docente deve possuir como as competências, as habilidades, os conhecimentos e o comportamento, Ignacio (2008, p.54) defende que a aprendizagem possui duas facetas, a primeira está ligada ao cíclico, aquilo que é repetitivo onde o aprender darse de maneira por associação. Para a segunda, vem a aprendizagem por reestruturação, Borges et al (2015, p.6) explica

Aprendizagem por sintonia - (tuning), que é um tipo de aprendizagem mais importante do que a anterior, na medida em que não é uma simples adição de informações à nossa base de conhecimentos, pois implica em modificações, ou pequenas sintonias, das categorias de conhecimentos que nós utilizamos para interpretar a informação. Corresponde a uma evolução de velhas estruturas de conhecimentos 
Aprendizagem por reestruturação - (restructuration) é o processo mais custoso em tempo e em esforço cognitivo (pode se estender por anos) porque ela implica a criação de novas estruturas ou categorias de conhecimentos, pois exige a presença de uma massa crítica de informações acumuladas ao longo dos anos. A aprendizagem por restruturação de Rumelhart \& Norman é muito próxima da aprendizagem por acomodação de Piaget.

Nessa perspectiva, é possível identificar que a natureza da aprendizagem se deve ao fato do mesmo ser contínua. O caráter contínuo da aprendizagem deve-se ao fato de a mesma permanecer em ininterrupta transmissão e retransmissão dos saberes, habilidades, concepções, conhecimento científico e, dessa forma, Antunes (2008, p.32) afirma que

Aprender é um processo que se inicia a partir do confronto entre a realidade objetiva e os diferentes significados que cada pessoa constrói acerca dessa realidade, considerando as experiências individuais e as regras sociais existentes.

Entendido o caráter multidisciplinar, interpessoal e constante sobre aprendizagem. É oportuno o olhar humano sobre essa temática, com isso, as normas, práticas e demais atos educacionais são uma questão de investigação contínua adaptando e se readaptando ao contexto de cada grupo.

Conforme anteriormente citado, é senso comum a dificuldade que os alunos de forma geral possuem no aprendizado em matemática. Dessa forma, é objeto de interesse desta parte textual verificar na bibliografia autores que tragam dados relativos à didática dos professores no que tange ao ensino de matemática e, também discorrer sobre os fatores que originam a dificuldade em matemática.

No introito desse texto, é conveniente explorar a didática do professor que é uma qualidade fulcral para o ensino, tendo em vista os expostos no que tange a comunicação verbal e não vergal. A vista disso, o professor como mediador do 
conhecimento pode em sua práxis pedagógica verificar as dificuldades dos alunos, e com isso fazer uma crítica reflexiva a fim de encontrar meios que tragam soluções nas dificuldades de aprendizagem. Nesse sentido, Costa (2009, p.1) faz colocações a respeito de "Quantas vezes você já ouviu comentários como esse ao formular um problema matemático para a turma? Os alunos ficam aflitos para saber qual operação usar e chegar ao resultado final e você, muitas vezes, precisa domar a tentação de dar a dica".

Conforme supracitado, é possível identificar na fala de Costa que o professor em muitos momentos menciona que o professor deve se conter a fim de deixar o aluno praticar seu conhecimento, ou, nesse contexto, também é possível formular que o professor durante sua pratica pedagógica pode estar desatento a forma de explicitar, porém, em ambos os casos, tem-se eventualmente o aluno se ver em conflito na identificação de "o que devo fazer?" e, por qual motivo devo fazer?.

Por conseguinte, é inteligível notar que comumente existe esse questionamento, onde durante a prática pedagógica o professor é questionado sobre a "utilidade" do que é exposto. Tais questionamentos podem ser facilmente vinculados ao fator de renda brasileira, no contexto onde a prática laboral é a necessidade urgente tendo em vista as necessidades fisiológicas conforme é explicado por Hesketh et al (1980, p.60) no que tange as motivações do indivíduo perante suas incumbências.

O autor supracitado explica como a Pirâmide de Maslow sistematiza conhecimentos para a motivação, essa motivação pode ser facilmente coadunada a realidade educativa, onde o aluno não tendo suas necessidades fisiológicas básicas atendidas não vislumbra motivação para a aprendizagem, com isso, é evidente que a condição financeira pode trazer impacto direto no processo de ensino-aprendizagem, tanto como instrumento motivador na mudança de realidade, ou, no aprofundamento de um estado desmotivador.

Tomando algumas teorias motivadoras no âmbito laboral em uma leitura no contexto educativo, é possível ainda citar a Teoria Motivação-Higiene produzida por Frederick Herzberg que segundo explica Manuel $(2017$, p.33) "[...] teoria dos dois fatores, os 
fatores higiénicos e os fatores motivacionais. Onde os fatores higiénicos referem-se às condições que rodeiam a pessoa, as condições físicas e ambientais [...]". Dessa forma, é possível vislumbrar que a motivação permeia muitas facetas, onde as condições fisiológicas e, ambientais podem trazer elementos desmotivadores ou, motivadores.

Para a tese deste trabalho, é inteligível aceitar que o indivíduo não tendo oportunidade de ter suas necessidades fisiológicas e ambientais atendidas, tem como consequência uma condição desmotivadora. Todavia, existe uma ótica interessante a ser examinada baseada em Schopenhuaer (2005, p.43)

"O mundo é minha representação." Essa é uma verdade que vale em relação a cada ser que vive e conhece, embora apenas o homem possa trazê-la à consciência refletida e abstrata. E de fato o faz. Então nele aparece a clarividência filosófica. Tornasse-Ihe claro e certo que não conhece sol algum e terra alguma, mas sempre um olho que vê um sol, uma mão que toca uma terra. Que o mundo a cercá-lo existe apenas como representação, isto é, tão somente em relação a outrem, aquele que representa, ou seja, ele mesmo.

Conforme citado, Schopenhuaer coloca dois saberes fundamentais, o primeiro está cimentado no conhecimento intuitivo, tendo em vista a fala onde o mundo é minha representação e, posteriormente na consciência refletida daquele que toma para si o conhecimento de mundo, perante a sua vivência, onde o saber se emerge a partir da vivência de mundo, onde o ser explora o ambiente e percebe o mesmo a partir do sensorial.

Outrossim, é colocado pela forma abstrata, essa pode ser colocada com a curiosidade de saber, uma vez que a curiosidade por muitas vezes moveu e move o mundo e, desta maneira o ser se move em sua motivação pela vontade de saber o desconhecido. Desta maneira, é oportuno destacar essa curiosidade no âmbito escolar, onde o cultivo sobre o perguntador deve ser fomentado em toda a trajetória escolar. 
Destarte, os estudos trazidos por Schwartz (2019, p.12) esclarecem que a motivação na aprendizagem diminui com o tempo escolar, onde a sua investigação aponta para vários motivos, como os institucionais tendo em vista a sistematização de um currículo engessado, a prática educativa pouco rica, fatores ambientais, familiares, dentre outros.

Assim sendo, as dificuldades de aprendizado em matemática se dão de forma não linear, mas sim, em um somatório de influenciadores que necessita de um trabalho contínuo e progressivo. Outrossim, é destacado conforme a fala de Sampaio (2019, p.22), onde esclarece sobre alguns fatores

Fatores orgânicos - saúde física deficiente, falta de integridade neurológica (sistema nervoso doentio), alimentação inadequada e etc.

Fatores psicológicos - inibição, fantasia, ansiedade, angustia, inadequação à realidade, sentimento generalizado de rejeição etc.

Fatores ambientais - o tipo de educação familiar, o grau de estimulação que a criança recebeu desde os primeiros dias de vida, a influência dos meios de comunicação etc.

No que tange a fala de Sampaio, é oportuno discutir os Fatores Ambientais. Para esses fatores, não é difícil encontrar na mídia social, nos meios de comunicação e, nas conversas informais, que a matemática é uma ciência difícil, onde sua aprendizagem requer certo grau de talento e sofrimento. Todavia, é fácil defender que tal assertiva não se sustenta, pois o aprendizado para toda ciência requer certo esforço, porém, o que se ver no discurso midiático é a implementação de um ideal de grande dificuldade.

O discurso midiático pulverizado pelas mídias sociais traz consequências à educação atualmente, tendo em vista que por meio dos fatores ambientais é solidificado no imaginário infantil que a aprendizagem em matemática é demasiadamente árdua. Nesse contexto, é evidente que é necessário mudar essa ideia, onde a aprendizagem pode ser realizada em ambas vertentes, em um esforço em conjunto entre os agentes 
institucionais da educação e o aluno, a outra vertente é relativa ao uso de tecnologias que fomentem a curiosidade, a saber, oportuno citar ações do canal no Youtube, Nostalgia.

\section{DIFICULDADES DO ENSINO E APRENDIZAGEM EM ESTATÍSTICA}

Para esta secção textual é pertinente buscar na bibliografia disponível autores que tenham encontrado as razoes para a dificuldade de aprendizagem na disciplina de estatística. Nessa conjuntura, foram feitas exposições sobre dificuldades de forma geral tanto no ensino, quanto na aprendizagem em matemática, porém, tomando de forma mais especifica, é oportuno tratar algumas dificuldades encontradas pelos alunos no entendimento sobre estatística, para isso, a Fig. 1 expõe alguns apontamentos.

Figura 1 - Dificuldades de alunos e professores em estatística

\section{Dificuldades e erros}

Frequência absoluta: no denominador da fracção colocar o valor da frequência absoluta e confundir o conceito de frequência absoluta com o de frequência relativa.

Gráficos: interpretar a informação presente num gráfico e identificar a variável em estudo e saber como a colocar no sistema de eixos.

Gráfico circular: estabelecer a proporção para encontrar o valor do ângulo, orientar o transferidor para marcar o sector circular e legendar o gráfico.

Gráfico de barras: decidir em qual dos eixos colocar a variável, construir a escala e legendar o gráfico.

Média: cálculo da média simples de duas médias dadas para determinar a média ponderada (lei do fecho).

Determinar um conjunto de dados, conhecidas a média, a mediana e a moda desse conjunto.

Inverter o algoritmo da média (raciocínio por tentativa e erro, lei do fecho, não ponderaram as médias dadas, uso incorrecto da fórmula da média e resolução errada da equação).

Possibilidade/impossibilidade da média e moda tomarem certos valores dados.

Âmbito de aplicação da média (variável nominal, média das frequências).

Âmbito de aplicação da mediana (variável nominal).

Determinar a média de dados agrupados (média das frequências e dos valores da variável).

Fonte: (António, 2009, p.6)

\section{7. $12 .^{\circ} \quad$ Futuros}

ano ano professores

$\checkmark$

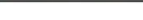

$\mathrm{RC}: 53277$

Disponível em: https://www.nucleodoconhecimento.com.br/educacao/matematica-na-perspectiva 
De acordo com a figura exposta, uma discussão ponderosa a ser trazida está posicionada em relação as dificuldades dos futuros professores, de acordo com a pesquisa, existem cinco pontos de dificuldades para os formandos e, na ótica desta trabalho, é uma quantidade considerável, que por sua vez é fonte de preocupação, visto que o professor deve estar munido do ferramental matemático e didático no conduzir das aulas na escola.

Portanto, tomando uma filosofia positivista, o que se espera sobre as dificuldades do ensino em estatística é construir um norte a ser seguido, não uma receita, ou conjunto de regras e práticas, mas sim, um conjunto dinâmico onde a adequação perante a realidade se molde em conjunto a realidade da instituição de ensino, do professor e do aluno.

Essa postura dinâmica da educação é ponto fulcral quando se tem acesso aos conhecimentos pedagógicos, saber fazer a reflexão-prática-crítica-prática na construção pedagógica certamente oferece instrumento prestigiado e, conforme as defesas desse artigo, o uso do cotidiano como instrumento de auxílio da práxis pedagógica no ensino de estatística deve ser norteador para o ensino.

\section{PROFESSORES E OS DESAFIOS DO ENSINO DE ESTATÍSTICA}

Com o advento do plano de orientação da Base Nacional Comum Curricular os debates sobre os desafios da educação frente a este documento são tema oportuno. Os estudos e reflexões sobre o BNCC já estão em curso desde 2012, segundo o MEC (2018, p.7) o documento teve sua construção "[...] por especialistas de todas as áreas do conhecimento, a Base é um documento completo e contemporâneo, que corresponde às demandas do estudante desta época, preparando-o para o futuro", a participação de especialistas de todas as áreas indica composição social democrática na construção do texto, além disso, vale ressaltar que o texto foi largamente assunto de discussões com o fomento de ideias e soluções em sua estrutura. Conforme mostra Campos (2015, p.357) 
esse debate assumiu novas configurações, tendo em vista o momento econômico-político do País, bem como as opções no interior do próprio Ministério de Educação, que acabou concebendo a Base não como uma proposta curricular político-pedagógica, conforme indica Freitas (2015), mas como um rol de competências que os alunos devem atingir.

Sobre essa temática fica evidente que o BNCC é um conjunto de orientações sobre as competências e habilidades que cada aluno deve alcançar ao fim de cada ciclo. Essa base comum não tem caráter de mostrar os processos de ensino-aprendizagem no cotidiano escolar, muito menos isolar o campo educacional de outras áreas da vida comum do cidadão, esta somente criando um quadro que deve ser usado como fundamento para a práxis pedagógica, a criação das competências se torna oportuna salientar, segue conforme o MEC (2018, p.8)

\section{SOBRE AS COMPETÊNCIAS GERAIS DA EDUCAÇÃO BÁSICA}

1. Valorizar e utilizar os conhecimentos historicamente construídos sobre o mundo físico, social, cultural e digital para entender e explicar a realidade, continuar aprendendo e colaborar para a construção de uma sociedade justa, democrática e inclusiva.

2. Exercitar a curiosidade intelectual e recorrer à abordagem própria das ciências, incluindo a investigação, a reflexão, a análise crítica, a imaginação e a criatividade, para investigar causas, elaborar e testar hipóteses, formular e resolver problemas e criar soluções (inclusive tecnológicas) com base nos conhecimentos das diferentes áreas.

3. Valorizar e fruir as diversas manifestações artísticas e culturais, das locais às mundiais, e também participar de práticas diversificadas da produção artístico-cultural.

O BNCC certamente ainda será fruto de debate, visto que o ensino é continuo e ininterrupto, além disso, existem outras vertentes sobre ensinos de em outras 
modalidades em curso. O debate certamente é o melhor caminho na tomada de decisões, a avaliação continuada conforme Saul revela (1995, 61) "A avaliação emancipatória apresenta dois objetivos básicos: iluminar o caminho da transformação e beneficiar as audiências", trata-se portanto não somente de um guia que deve ser seguido arrisca, mas sim, questionado, modificado, melhorado e discutido com a ênfase de melhor práxis pedagógica, o sociedade como ente participativo de tal discussão é fundamento de enorme interesse no que tange ao valor ótimo de aprendizagem.

Nesse contexto, a BNCC traz alguns pontos norteadores para o ensino de matemática, onde segundo Brasil (2018, p.245) a matemática não pode ser restrita a quantificação de fenômenos, mas sim oferecer subsídios ao aluno de modo a que o mesmo seja capaz de identificar o contexto e aplicar procedimentos na solução de problemas.

Essas recomendações supracitadas estão inseridas em diversas facetas da matemática, todavia, para os objetivos deste trabalho a estatística é o objeto de interesse e, desta maneira a BNCC orienta que o ensino desta área do conhecimento tenha enfoque no letramento matemático, pois é necessário aprimorar habilidades de modo a raciocinar, representar, comunicar e argumentar matematicamente (BRASIL, 2018, p.268).

Desta maneira, no que tange aos objetivos elencados pela BNCC, vale ressaltar segundo mostra Brasil (2018, p.267)

1. Reconhecer que a Matemática é uma ciência humana, fruto das necessidades e preocupações de diferentes culturas, em diferentes momentos históricos, e é uma ciência viva, que contribui para solucionar problemas científicos e tecnológicos e para alicerçar descobertas e construções, inclusive com impactos no mundo do trabalho. 
2. Desenvolver o raciocínio lógico, o espírito de investigação e a capacidade de produzir argumentos convincentes, recorrendo aos conhecimentos matemáticos para compreender e atuar no mundo.

Tomando para análise o segundo objetivo citado, é importante observar que o documento educativo deixa claro sobre os conhecimentos sobre incerteza, onde é necessária uma abordagem dos problemas de situações-problema da vida cotidiana (BRASIL, p.274), onde a estatística possui o papel de se usada na coleta e organização de dados de uma pesquisa, uma vez que o sugerido é pautado na aplicação cotidiana da realidade dos alunos.

Nessa conjuntura, tratando de modo taxativo as sugestões elencadas na BNCC vêm sobre esta parte textual que Brasil (2018, p.281)

Probabilidade e estatística Noção de acaso (EF01MA20) Classificar eventos envolvendo o acaso, tais como "acontecerá com certeza", "talvez aconteça" e "é impossível acontecer", em situações do cotidiano. Leitura de tabelas e de gráficos de colunas simples (EF01MA21) Ler dados expressos em tabelas e em gráficos de colunas simples. Coleta e organização de informações Registros pessoais para comunicação de informações coletadas (EF01MA22) Realizar pesquisa, envolvendo até duas variáveis categóricas de seu interesse e universo de até 30 elementos, e organizar dados por meio de representações pessoais.

Uma conclusão importante a ser retirada das recomendações vem sobre o fato o uso do cotidiano, esse instrumento de ensino é recorrente nas recomendações de diversos autores, tendo em vista que é inteligível verificar que a aplicação dos conhecimentos estudantis em situações-problema da realidade do aluno oferece insumos a aprendizagem, a memória e a prática dos saberes e conhecimentos colocados em sala de aula.

O uso do cotidiano como instrumento de auxilio no processo de ensino-aprendizagem em matemática é defendido segundo a fala de Gonçalves et al (2018, p.994) tendo 
em vista a intersecção entre a estatística e a probabilidade, uma vez que é necessário ofertar a prática de situações-problema nas tomadas de decisões, quanto a análise da coleta de dados, fazendo desta forma uma construção progressiva e contínua durante o percurso do aluno no ensino fundamental.

Portanto, fica evidente que o professor durante a sua práxis pedagógica em matemática, deve estar atento a alguns apontamentos da BNCC, uma vez que a exposição e prática do conhecimento devem conter qualidades progressivas, fazendo ligações com a realidade do aluno, por conseguinte, é necessário conhecer a vivência da comunidade e estar atento a essa contextualização.

\section{PERSPECTIVAS SOBRE O ENSINO EM MATEMÁTICA}

A Matemática sempre foi vista como uma disciplina que traz muito incomodo e que não há nenhum atrativo, o que faz dela ser tão temida é suas regras e teorias bastante abstrata e que não coincidem com a realidade vivida, a disciplina de matemática é apontada como extremamente difícil, pois trabalha com figuras e teorias muito abstratas que foge da realidade das pessoas.

Para tanto, surgiu as TIC com objetivo de diminuir as paralisias no ensino e proporcionar um desenvolvimento significativo, contudo sua implementação ainda é vista como algo a ser encorajado, uma vez que existem alguns entraves quanto a estrutura e as metodologias práticas de ensino.

O que acontece é que há distintas possibilidades que através dessas mídias que o discente poderá ser capaz de aprimorar suas próprias aptidões, fazendo por sua vez hipóteses e verificando através de simuladores os conceitos aprendidos. Com isso, mostra-se a relevância do professor ao pesquisar novas metodologias que podem contribuir na concepção do conhecimento, desta maneira defende (BORIN E GROENWALD, 2008, p. 1)

(...) a introdução de jogos nas aulas de Matemática é a possibilidade de diminuir bloqueios apresentados por muitos de nossos alunos que 
temem a Matemática e sentem-se incapacitados para aprendê-la. Dentro da situação de jogo, onde é impossível uma atitude.

Uma vez estabelecida às diretrizes para cada atividade, as necessidades de ministrar os saberes é feito em uma análise sobre a prática educativa. A busca pelas dimensões sobre as diferentes formas de ensinar normalmente é realizada de maneira crítica, reflexiva e investigativa, esses tópicos norteiam a práxis pedagógica e também fornece um caminho para os alunos que são agentes ativos de sua aprendizagem, baseado nesse caminho norteador, Zabala (2001, p. 19) esclarece que "[...] O meio do ensino/aprendizagem entre aluno e professor e matéria, que inclui narrar e referir, mostrar e imitar ou reproduzir, a observação comum dos objetos ou imagens, ler e escrever; a dimensão dos conteúdos de aprendizagem [...]", ou seja, os elementos que Zabala lista podem facilmente ser vinculados a plataformas que possuem fácil acesso por dispositivos eletrônicos.

Nesse viés, a BNCC destaca que o jogo no ensino da matemática é um modelador, ou seja, as figuras, a linguagem envolvida , os exercícios que envolvem , as diversas habilidades que se conquistam ao decorrer do jogo, são exemplos reais do que é a matemática e a geometria , ainda mais que se tem uma estrutura lógica por trás. Assim afirma (RODRIGO BLANCO, 2017):

A matemática, pelo viés da BNCC, não é só um manancial de números, operações e formas geométricas: é, também, um jogo, uma linguagem, uma forma de ver e modelar realidades, uma estrutura de pensamento, um exercício criativo e um campo de desenvolvimento de múltiplas habilidades. Pode ser que nem sempre as aplicações sejam práticas, mas certamente essa nova visão torna seus conteúdos muito mais interessantes.

A partir de 2016, com a elaboração das competências gerais da base comum curricular (BNCC), a matemática ganha uma nova abordagem para o ensino nas escolas, a proposta de uma educação voltada para cidadania, ajudando ao aluno ser mais crítico e consciente das oportunidades que a matemática propõe para seu 
cotidiano, passa então a ser muito discutida e inserida na prática de alguns professores, principalmente porque coloca o aluno com participante no processo de ensino- aprendizagem.

Para isso existem competências definidas pela BNCC os jogos digitais e as TIC no ensino da matemática devem primeiramente ter um caráter pedagógico e que a elaboração desses recursos possa de alguma forma criar um aprendizado critico, significativo, reflexivo e ético, sendo que nas inúmeras rotinas da sociedade (incluindo as escolares) as TICs possa transmitir informação, produção de conhecimento, resolver problemas e possa desenvolver a autonomia do aluno, "Utilizar processos e ferramentas matemáticas, inclusive tecnologias digitais disponíveis, para modelar e resolver problemas cotidianos, sociais, de outras áreas do conhecimento, validando estratégias e resultados." (BNCC, 2019).

A BNCC adverte que o conhecimento vai além de um livro, de um programa educacional ou de uma atividade. Devem-se buscar mais estratégias que solucione problemas de forma produtiva e tecnológica, ou seja, a interdisciplinaridade, novas formas de ensinar e novas competências em orientar.

Quanto às exatas, o documento normativo incentiva que os discentes busquem semelhanças do mundo real com a matemática, de forma que a criatividade e o pensamento crítico possam colaborar de modo que o professor não terá apenas um papel - o de calcular, mais sim demonstrar para os alunos o que está por trás das relações matemática, trazendo aplicabilidade a curto, médio e longo prazo.

Vale ressaltar que a criança ao resolver o problema deve aprender a esclarecer o motivo do resultado, demonstrando o seu raciocínio com os demais colegas e professores. Desta maneira, ainda permeando sobre o uso dos jogos digitais, Prensky (2012) afirma que os jogos devem ter os seguintes elementos: regras que guiem as práticas, propósitos ou metas que motivem às realizações, consequências que indiquem os feedbacks das ações, problemas que estimule a continuidade sobre a prática. 


\section{CONSIDERAÇÕES FINAIS}

Para essa discussão final, é interessante expor de forma resumida que existem muitos desafios a serem solucionados no que tange o ensino de matemática. Por conseguinte, é necessário manter a investigação e reflexão no contexto escolar e acadêmico, a fim de trazer conclusões que tragam métodos de ensino.

Nessa perspectiva, vem sobre a discussão à prática do ensino em um contexto do cotidiano, a fim de trazer qualidades à prática pedagógica, fomentando nessa perspectiva a motivação no aprendizado em matemática, melhorando a didática em sala de aula, trazendo qualidades inclusivas que por sua vez complementem de modo positivo o ensino de matemática.

O BNCC certamente ainda será fruto de debate, visto que o ensino é continuo e ininterrupto, além disso, existem outras vertentes sobre ensinos de em outras modalidades em curso. O debate certamente é o melhor caminho na tomada de decisões, trata-se, portanto, não somente de um guia que deve ser seguido arrisca, mas sim, questionado, modificado, melhorado e discutido com a ênfase a melhor práxis pedagógica, a sociedade como ente participativo de tal discussão é fundamento de enorme interesse no que tange ao valor ótimo de aprendizagem.

Por fim, é necessário rever, aprimorar e adaptar diversas práticas educativas, tanto no âmbito da exposição didática do conteúdo, quanto à atenção perante o currículo. Desse modo, refletir no âmbito acadêmico na reformulação continuada do currículo escolar torna-se papel dos agentes educativos, pois a educação necessita de incessante regeneração.

\section{REFERÊNCIAS}

ANTUNES, Celso. Professores e professauros: reflexões sobre a aula e prática pedagógica diversas. 2.ed. Petrópolis, RJ: Vozes, 2008.
ANTÓNIO, José F. ENSINO E APRENDIZAGEM DA ESTATÍSTICA: REALIDADES E DESAFIOS.
Disponível: 
https://repositorium.sdum.uminho.pt/bitstream/1822/9368/1/2009a\%20XIX\%20EIEM. pdf>

BORGES, O. Martin; DOS SANTOS, Neri; F, Luciano de Medeiros. COGNIÇÃO E APRENDIZAGEM SITUADA: DA ASSOCIAÇÃO À APRENDIZAGEM POR REESTRUTURAÇÃO. Revista Intersaberes| v. 10, n. 20, p. 155-203| jan./abr., 2015| 1809-7286.

BERGAMINI, M. Campos; MELCHIADES, Amarildo da Silva. A EDUCAÇÃo FINANCEIRA NA MATEMÁTICA DO ENSINO FUNDAMENTAL. Disponível em:<http://www.ufj.br/mestradoedumat/files/2011/09/Produto-Educacional-MarceloBergamini-Campos.pdf>

BRASIL. MINISTÉRIO DA EDUCAÇÃO. BASE NACIONAL COMUM CURRICULAR. Disponível:http://basenacionalcomum.mec.gov.br/images/BNCC_El_EF_110518_ver saofinal_site.pdf>

COSTA, Carolina. Como se aprendem adição e subtração. Revista Nova Escola. São Paulo: Fundação Victor Civita, 2007, p.67-78. Disponível em:<https://novaescola.org.br/conteudo/2671/somar-e-subtrair-operacoes-irmas>

GONÇALVES, S. Vilas Bôas; CRISTINA, Keli Conti. Base Nacional Comum Curricular: um olhar para Estatística e Probabilidade nos Anos Iniciais do Ensino Fundamental. Ensino Em Re-Vista | Uberlândia, MG | v.25 | n.Especial | p. 984-1003 | 2018.

IGNEZ, Ana Nunes B. Lima. Psicologia da aprendizagem. 3 ed. Fortaleza: EduECE, 2015.

IGNACIO, Juan Pozo. Aprendizes e mestres: a nova cultura da aprendizagem. Porto Alegre: Artmed, 2008. 
HESKETH, José Luiz; COSTA, Maria. T.PM. CONSTRUÇÃO DE UM INSTRUMENTO PARA MEDIDA DE SATISFAÇÃO NO TRABALHO. Disponível em:<http://www.scielo.br/pdf/rae/v20n3/v20n3a05>

MANUEL, Bruno A. Gonçalves. A motivação e satisfação no trabalho: importância, fatores, relacionamentos e consequências. Disponível em:<https://bdigital.ufp.pt/bitstream/10284/6621/1/DM_Bruno\%20Gon\%C3\%A7alves .pdf>

SCHOPENHUAER, Arthur. O mundo como vontade e como representação. Tradução Jair Barboza. São Paulo: Unesp, 2005.

SAUL, A. M. Avaliação emancipatória: desafios à teoria e à prática de avaliação e reformulação de currículo. 3.ed. São Paulo: Cortez, 1995.

SAMPAIO, Simaia. Dificuldades de APRENDIZAGEM. 5 ed. Rio de Janeiro: Wak Editora, 2019.

SCHWARTZ, Suzana. Motivação para ensinar e aprender: teoria e prática. Petrópolis, Rio de Janeiro: Vozes, 2019.

Enviado: Junho, 2020.

Aprovado: Junho, 2020. 